\title{
PROPRIEDADES TERMOFÍSICAS DA MISTURA DE PELE/GORDURA DE FRANGO: INFLUÊNCIA DA TEMPERATURA E DO CONTEÚDO DE UMIDADE
}

\author{
T. E. J. PEREIRA ${ }^{1}$, G. R. STRÖHER ${ }^{1}$ e J. F. NICOLETI ${ }^{1}$ \\ ${ }^{1}$ Universidade Tecnológica Federal do Paraná, Campus Apucarana, Departamento de \\ Processos Químicos \\ E-mail para contato: nicoleti@utfpr.edu.br
}

\begin{abstract}
RESUMO - A mistura da pele e gordura de frango pode ser útil para a formulação de ração animal, na obtenção do colágeno para a fabricação de gelatina, como ingrediente na fabricação de sabão e na produção de biodiesel. $\mathrm{O}$ comportamento das propriedades termofísicas - condutividade térmica, difusividade térmica e massa específica - da mistura de pele e gordura de frango, em função do conteúdo de umidade e da temperatura do produto, foi investigado nesta proposta. A condutividade térmica foi avaliada pelo método da sonda linear com geração interna de calor, a difusividade térmica baseou-se no método de Dickerson, enquanto a massa específica foi quantificada por picnometria. De uma forma geral, os valores da condutividade e difusividade térmicas da mistura pele/gordura tiveram um aumento conforme a temperatura e o conteúdo de umidade foram aumentados, sendo a condutividade térmica mais afetada. Em relação à massa específica, o comportamento desta grandeza foi inverso ao observado com as anteriores.
\end{abstract}

\section{INTRODUÇÃO}

Dos produtos industrializados que empregam a carne de frango destacam-se os empanados, pastas ou patês de frango, embutidos fermentados e produtos reestruturados (Roque, 1996). Em relação à pele e gordura de frango que não são aproveitadas para o consumo humano, estas são úteis na formulação de ração animal, na obtenção do colágeno para a fabricação de gelatina, como ingrediente na fabricação de sabão e na produção de biodiesel (Galão et al., 2003; Racanicci et al., 2004).

Seja na preparação de alimentos que emprega a carne de frango ou na operação de unidades fabril em que a pele/gordura de frango são matérias primas, quase sempre há uma demanda de energia. As propriedades termofísicas de alimentos, entre elas o calor específico, condutividade térmica, difusividade térmica e densidade, são parâmetros relevantes na otimização de projetos e operações que envolvem processos térmicos (Karunakar et al., 1998). De acordo com Unklesbay et al. (1999), estas propriedades térmicas, além de serem essenciais na modelagem e avaliação de operações de processamento de alimentos que envolvem transferência de calor, são especialmente importantes quando os custos de energia, qualidade e segurança alimentar são considerados. 
Marcotte et al. (2008) avaliaram a condutividade térmica, calor específico, difusividade térmica e densidade de emulsões a partir de carnes e aves domésticas processadas (mortadela bolonhesa, lingüiça italiana, peru, presunto e salsicha defumada). Como resultados, encontraram que a condutividade térmica aumentou linearmente com o aumento da temperatura entre 20 e $60{ }^{\circ} \mathrm{C}$, permanecendo constante entre 60 e $80{ }^{\circ} \mathrm{C}$ para a maioria dos produtos, exceto para a mortadela bolonhesa. A densidade teve uma pequena queda em função da temperatura entre 20 e $40{ }^{\circ} \mathrm{C}$, seguida de um aumento até $60{ }^{\circ} \mathrm{C}$, voltando a apresentar um decréscimo até a temperatura final de $80{ }^{\circ} \mathrm{C}$. Tanto a densidade quanto o calor específico foram fortemente influenciados pelo teor de carboidratos, enquanto a condutividade e a difusividade térmicas foram afetadas pelo conteúdo de sal.

Carne bovina magra, gordura e suas misturas em proporções de 1:1 foram investigadas por Farag et al. (2008) na determinação das propriedades térmicas em função da temperatura num alcance de -18 e $10^{\circ} \mathrm{C}$. Considerando a natureza das três matérias-primas, os valores da condutividade térmica, calor específico e difusividade térmica foram inferiores conforme os teores de gordura eram aumentados, avaliados numa mesma faixa de temperatura.

Embora alguns modelos matemáticos da literatura possam ser usados para a obtenção dos parâmetros termofísicos em função da composição de sistemas alimentícios e temperatura (Karunakar et al., 1998; Gonzo, 2002; Wang et al., 2006; Carson, 2006), há um consenso que estes modelos não podem ser empregados indiscriminadamente devido aos desvios causado pela complexidade das matérias alimentícias (Marcotte et al., 2008).

Apesar de os valores das propriedades termofísicas da carne de frango poderem ser conseguidas através destas correlações empíricas, há uma carência de informações experimentais considerando a carne de frango nacional e dados mais atuais, o que contribui com a relevância desta investigação. Como justificativa adicional está a expansão do setor industrial avícola do estado do Paraná e sua contribuição econômica e social à região. Desta forma, o objeto deste trabalho foi determinar experimentalmente as propriedades termofísicas - condutividade térmica, difusividade térmica e densidade - da mistura de pele e gordura de frango em função do conteúdo de umidade e da temperatura do produto.

\section{MATERIAL E MÉTODOS}

A pele e gordura de frango foram retiradas das partes do peito e da coxa/sobrecoxa resfriadas adquiridas da empresa Big Frango, situada no município de Rolândia, Paraná, Brasil. Após a separação da pele e da gordura das carnes, esta mistura foi estocada em freezer doméstico $\left(-18^{\circ} \mathrm{C}\right)$ para as análises posteriores.

Tanto para a quantificação da composição centesimal mistura pele/gordura de frango quanto para os ensaios experimentais na determinação de suas propriedades termofísicas, a mistura foi descongelada em refrigerador $\left(1^{\circ} \mathrm{C}\right)$ por $48 \mathrm{~h}$, e em seguida trituradas em um moedor de carne (Marca Arbel, Modelo MTU 08) e misturadas manualmente.

\subsection{Composição Centesimal}

A composição centesimal do mix de pele/gordura de frango foi avaliada em 6 réplicas para o cálculo da média. O conteúdo de umidade foi determinado pelo método gravimétrico 
em estufa de circulação forçada (AOAC, 1997) a uma temperatura de $105^{\circ} \mathrm{C}$ por $3 \mathrm{~h}$; a quantificação do teor de lipídeos totais foi de acordo com a técnica proposta por Blingh e Dyer (1959) empregando clorofórmio e metanol como solventes; a avaliação de proteínas foi feita pelo método de determinação de nitrogênio total kjeldahl (AOAC, 1997) pela transformação da matéria orgânica em sulfato de amônio em um digestor, seguindo para as etapas de neutralização com $\mathrm{NaOH}$ e destilação do nitrogênio, por fim, titulou-se o destilado com ácido clorídrico padronizado; as cinzas totais foram determinadas por incineração da amostra em forno mufla com temperatura programada em torno de $550{ }^{\circ} \mathrm{C}$ por $4 \mathrm{~h}(\mathrm{AOAC}$, 1997) e o resultado obtido por diferença de massa antes e após incineração.

\subsection{Propriedades Termofísicas}

Para avaliar o efeito do teor de umidade sobre as propriedades termofísicas, a redução do conteúdo de umidade das carnes da coxa/sobrecoxa de frango moídas foi conseguida com auxílio de uma estufa de circulação forçada (Marca Marconi, Modelo MA 033/216) a $60{ }^{\circ} \mathrm{C}$, no qual as carnes foram dispostas sobre bandejas em seu interior. Além da carne in natura reservada, em quatro tempos pré-programados e subseqüentes parcelas de amostras eram retiradas do interior da estufa, totalizando desta forma, cinco conteúdos de umidades distintos.

\section{Condutividade térmica}

As medidas da condutividade térmica foi conseguida pela metodologia da sonda linear em regime transiente, confeccionada com resistência elétrica níquel-cromo e termopar isolados eletricamente entre si em seu interior (Sahin \& Summu, 2006). O aparato de cilindro de alumínio $(\mathrm{L}=27,5 \mathrm{~cm}, \mathrm{D}=5,30 \mathrm{~cm}$ ) utilizado nos experimentos foi previamente calibrado com água imobilizada empregando carragena 1\% (p/p) (Oliveira et al., 2005). As amostras, com distintos teores de umidade para cada ensaio, foram introduzidas no cilindro de alumínio e compactadas para remoção de bolsas de ar. Em seguida, a sonda foi inserida em seu centro geométrico, contendo a amostra, e o conjunto (cilindro-amostra-sonda) foi devidamente vedado para mergulhá-lo em um banho ultratermostatizado (Marca Marconi, Modelo MA184) com água. Após a amostra entrar em equilíbrio com as temperaturas pré-programadas (5 - $80{ }^{\circ} \mathrm{C}$ ) do banho, uma corrente elétrica (1 A) foi gerada com auxílio de um fonte de tensão controlada de $10 \mathrm{~V}$ e lida por um amperímetro, enquanto a temperatura era registrada a cada segundo por um registrador de dados Field Logger (Marca Novus).

O equacionamento para este sistema foi baseado na equação da conservação da energia em coordenadas cilíndricas, fluxo de calor radial, com geração interna de calor e condutividade térmica constante. De acordo com as condições de contorno apropriadas, temse como solução analítica a equação (1) (Sahin e Summu, 2006).

$$
T_{2}-T_{1}=\frac{\dot{Q}}{4 k \pi} \ln \left(\frac{t_{2}}{t_{1}}\right)
$$

Com o valor da taxa de transferência de calor por metro linear da sonda térmica $(\dot{\mathrm{Q}})$ calculado pela equação (2), e a partir dos pontos experimentais de temperatura $(\mathrm{T})$ e tempo $(\mathrm{t})$, avaliados na faixa linear compreendida entre os pontos inicial (subscrito 1) e final (subscrito 
2), foi possível obter os valores de k pelo coeficiente angular da Eq. (1), obtido por uma regressão linear.

$$
\dot{Q}=\frac{U . i}{l}
$$

sendo $\mathrm{U}$ a tensão $(10 \mathrm{~V})$, i a corrente elétrica $(1 \mathrm{~A})$ e $l$ o comprimento $(0,22 \mathrm{~m})$ do fio de resistência elétrica.

\section{Difusividade térmica}

A difusividade térmica foi avaliada pelo método de Dickerson (1965) empregando um cilindro de bronze com as dimensões $\mathrm{R}=15 \mathrm{~mm}$ e $\mathrm{L}=220 \mathrm{~mm}$ previamente calibrado com água imobilizada empregando carragena $1 \%(\mathrm{p} / \mathrm{p})$ (Oliveira et al., 2005). O cilindro foi preenchido com as amostras e termopares tipo K foram alocados em seu centro geométrico e na parede para em seguida, ser submerso em banho ultratermostatizado (Marca Marconi, Modelo MA-184). A elevação de temperatura do banho foi programada na faixa de 5 a $90{ }^{\circ} \mathrm{C}$, a uma taxa de $2{ }^{\circ} \mathrm{C} / \mathrm{min}$, e registrada a cada segundo por um registrador de dados Field Logger (Marca Novus).

O equacionamento foi baseado na equação da conservação da energia em coordenadas cilíndricas, regime transiente, fluxo de calor radial, sem geração interna de calor, condutividade térmica e taxa de elevação de temperatura constante $(\mathrm{dT} / \mathrm{dt}=\mathrm{A})$. De acordo com as condições de contorno apropriadas, tem-se como solução analítica a Equação (3):

$$
\left(T_{R}-T_{c}\right)=\frac{A}{4 \alpha} R^{2}
$$

onde $\mathrm{R}$ é o raio do cilindro com temperatura correspondente a $T_{R}, T_{c}$ a temperatura do centro do cilindro, A a taxa (dT/dt) de elevação de temperatura $\left({ }^{\circ} \mathrm{C} / \mathrm{min}\right)$ e $\alpha$ a difusividade térmica.

Com os valores de $\mathrm{A}$, da diferença de temperaturas da parede e do centro do cilindro $\left(T_{R}-T_{c}\right)$ avaliados na faixa linear e do raio do cilindro $(R)$ foi possível obter os valores da difusividade térmica $(\alpha)$ a partir da equação (3) em função da temperatura média $[(\mathrm{TR}+\mathrm{Tc}) / 2]$.

\section{Massa específica}

A massa especifica foi avaliada por picnometria (Mohsenin, 1986) empregando etanol PA como fluido picnométrico. A escolha deste fluido se deu por não ser reativo às amostras, ser não-voláteis, não ter ação de solvente, por não ser tóxicos e possuir densidade inferior à matéria-prima. Os picnômetros foram previamente calibrados com água destilada a temperatura ambiente. A elevação de temperatura foi conseguida imergindo o picnômetro com as amostras em banho ultratermostatizado (Marca Marconi, Modelo MA-184) com varredura de temperatura entre 5 e $80^{\circ} \mathrm{C}$.

\section{RESULTADOS E DISCUSSÃO}


$\mathrm{Na}$ avaliação da composição centesimal da mistura de pele e gordura de frango avaliada neste trabalho, a média das seis réplicas apresentou 45,09 $( \pm 1,04) \%$ de água, 8,06 $( \pm 0,43) \%$ de proteínas, 44,67 $( \pm 1,07) \%$ de lipídeos, $0,98( \pm 0,07) \%$ de cinzas, e por diferença, $1,20 \%$ de carboidratos. Valores próximos ao encontrado neste trabalho podem ser conferidos em TBCA/USP (1998) que relaciona a composição da pele de frango como sendo de $49,03 \%$ de água, $7 \%$ de proteínas, $43 \%$ de lipídeos e $0,97 \%$ de cinzas.

Considerando os valores da difusividade térmica do mix de pele e gordura de frango em função do conteúdo de umidade (x) e da temperatura da amostra média, seu comportamento é ilustrado pela Figura 1. Os valores encontrados para esta propriedade nos limites de temperatura e conteúdos de umidade avaliados estão entre $0,98.10^{-7} \mathrm{~m}^{2} / \mathrm{s}$ e $1,08.10^{-7} \mathrm{~m}^{2} / \mathrm{s}$. Cengel (2004) reportou a difusividade térmica da carne de peito de frango, a $0{ }^{\circ} \mathrm{C}$, num valor de $1,30.10^{-7} \mathrm{~m}^{2} / \mathrm{s}$ e nos experimentos de Huang \& Liu (2009) o valor encontrado foi $1,524.10^{-}$ ${ }^{7} \mathrm{~m}^{2} / \mathrm{s}$, porém este autores não informam a temperatura do produto.

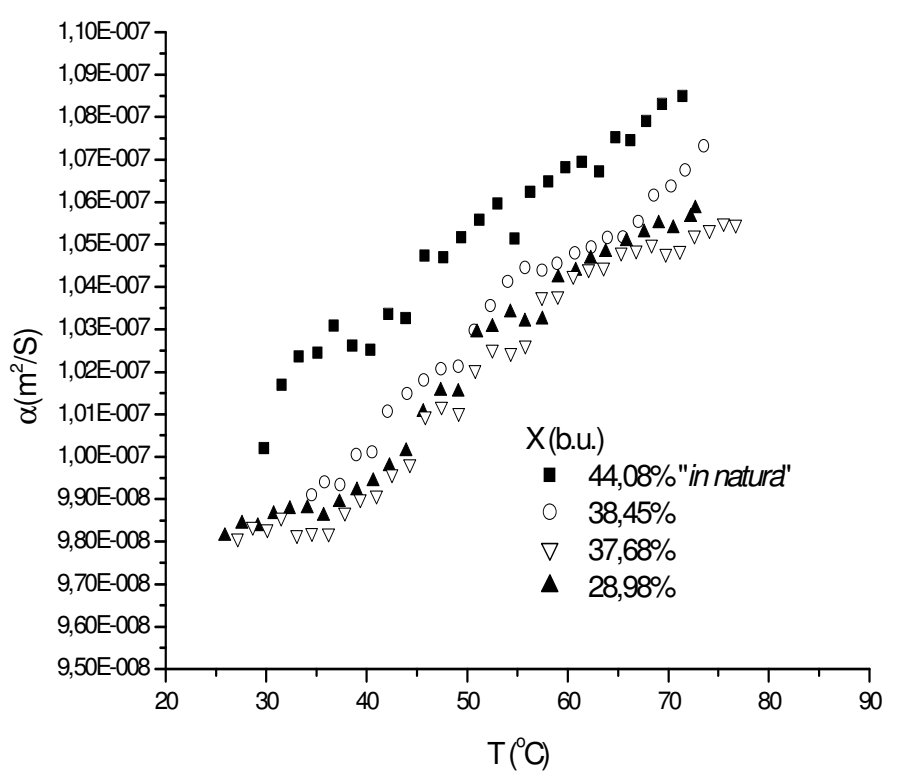

Figura 1 - Difusividade térmica da mistura de pele/gordura de frango em função do teor de umidade e temperatura.

Observa-se que apesar do espaçamento da curva representada pelo maior conteúdo de umidade da amostra, estando acima das demais condições de umidade, de um modo geral, pode-se considerar que a difusividade térmica praticamente não é influenciada pelo teor de umidade. As três curvas das amostras de teor de umidade menores acabam que se sobrepondo, enquanto que a curva superior, mesmo que estando afastada das demais, representa um aumento nos valores da difusividade térmica em média de apenas $3 \%$ comparado a um valor médio da difusividade térmica das três curvas mais abaixo.

Os valores da condutividade térmica também foram investigados em função do conteúdo de umidade $(\mathrm{X})$ e da temperatura média da amostra. A Figura 2 apresenta este 
resultado para a mistura de pele e gordura de frango. Comparando os resultados encontrados da condutividade térmica com o da difusividade térmica, nota-se que o teor de umidade tem mais influência sobre a primeira propriedade, observado agora pelo espaçamento entre as retas representativa da condutividade térmica para um conteúdo de umidade fixo.

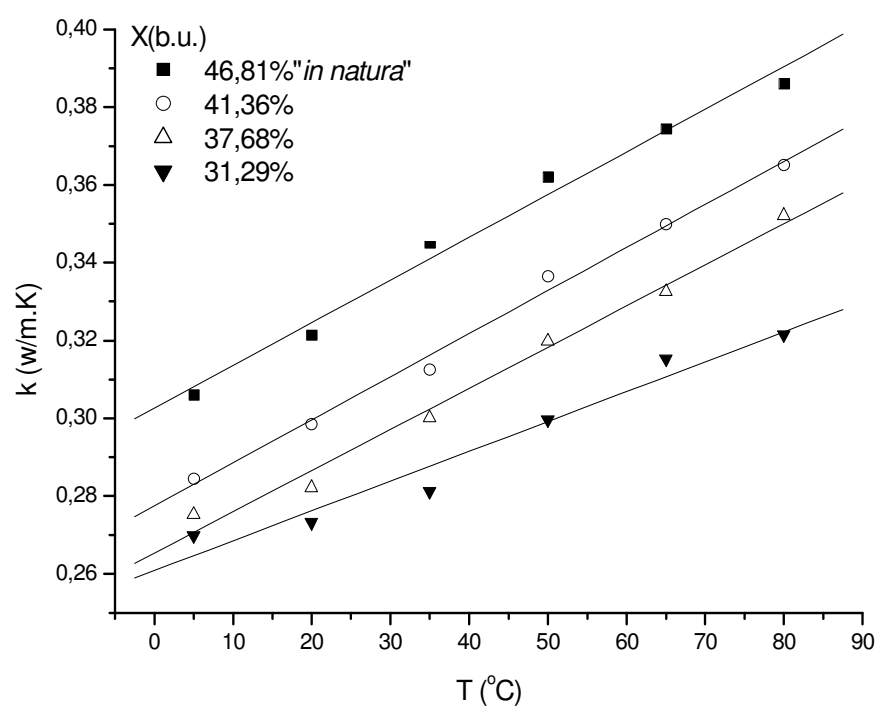

Figura 2 - Condutividade térmica da mistura de pele/gordura de frango em função do teor de umidade e temperatura.

A faixa de valores da condutividade térmica encontrada nas condições experimentais avaliadas ficou entre 0,27 e $0,39 \mathrm{~W} / \mathrm{m} . \mathrm{K}$, observando-se uma clara tendência de seus valores aumentar com a elevação da temperatura (T) e com o aumento do conteúdo de umidade $(\mathrm{X})$. Marcotte et al. (2008) encontraram para a carne de peru, com conteúdo de umidade de $74,88 \%$, os valores da condutividade térmica entre 0,332 e $0,482 \mathrm{~W} / \mathrm{m} . \mathrm{K}$ nas temperaturas de 22 e $79{ }^{\circ} \mathrm{C}$, respectivamente. Optou-se por um ajuste linear aos pontos experimentais, com coeficiente de correlação $(\mathrm{R})$ superior a 0,98 para a condição menos favorável à linearidade.

Os dados da massa específica da carne de frango em função da temperatura e do conteúdo de umidade são apresentados na Figura 3. Há uma nítida tendência dos valores da massa específica aumentarem conforme o teor de umidade é reduzido. Em relação à temperatura, seu efeito sobre a massa específica é reduzi-la de de acordo com sua elevação, em especial a partir de $20{ }^{\circ} \mathrm{C}$, pois observa-se que em temperatura inferior há uma leve tendência dos valores da massa específica permanecerem inalterados, é o que aponta ao menos a temperatura de $5^{\circ} \mathrm{C}$.

Para a condição in natura da amostra da mistura de pele e gordura de frango, em temperatura de $20{ }^{\circ} \mathrm{C}$, o valor da massa específica ficou próxima de $1,00 \mathrm{~g} / \mathrm{cm}^{3}$. Marcotte et al. (2008) encontraram que os valores desta propriedade térmica para diversos produtos a base de carne de aves domésticas ficaram na faixa entre $1,035 \mathrm{~g} / \mathrm{cm}^{3}$ e $1,055 \mathrm{~g} / \mathrm{cm}^{3}$ tomados em temperatura próxima de $22{ }^{\circ} \mathrm{C}$, entretanto, este autores trabalharam com emulsões cárneas de produtos processados. 


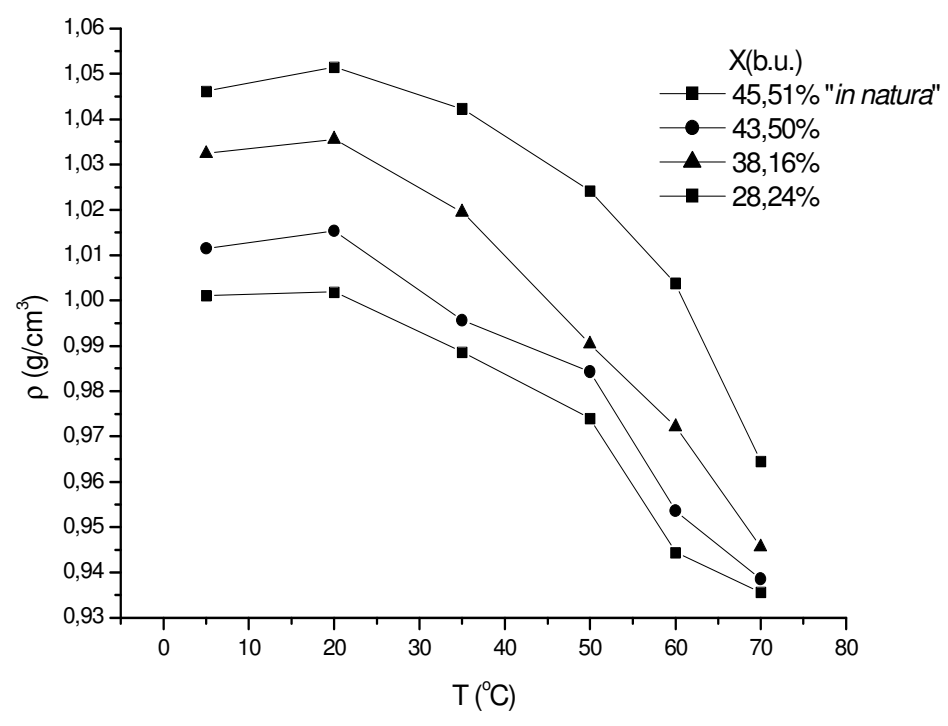

Figura 3 - Massa específica da mistura de pele/gordura de frango em função do teor de umidade e temperatura.

Marcotte et al. (2008) encontraram uma brusca redução nos valores da massa específica de produtos cárneos a partir de $60{ }^{\circ} \mathrm{C}$. $\mathrm{O}$ mesmo comportamento foi verificado com a mistura pele/gordura de frango, porém, neste caso, esta queda pode ser notada em temperaturas superiores a $20{ }^{\circ} \mathrm{C}$. Segundo Marcotte et al. (2008) esta queda nos valores da densidade pode ser possivelmente pela gelificação da proteína da carne que provoca um pequeno aumento do volume da amostra.

\section{CONCLUSÕES}

Das três propriedades termofísicas avaliadas, a difusividade térmica foi a menos afetada pelo conteúdo de umidade, enquanto que a temperatura influenciou todas. Os valores da condutividade térmica tiveram um aumento conforme o teor de umidade também era aumentado, enquanto a massa específica apresentou um resultado inverso, com amostras mais densas à medida que a quantidade de umidade era diminuída. $\mathrm{O}$ efeito do aumento da temperatura conduziu a uma elevação nos valores da difusividade e condutividade térmica, por outro lado, para a massa específica, o efeito da temperatura ser aumentada foi inverso, levando a uma redução em seus valores.

\section{AGRADECIMENTOS}

Os autores agradecem o Auxílio Financeiro concedido pelo CNPq (Proc.473092/20093) e à Fundação Araucária pela Bolsa de Iniciação Científica (PIBIC 2009/2010 e 2010/2011).

\section{REFERÊNCIAS}


AOAC. Association of Official Analytical Chemists. Official methods of analysis of the Association of Analytical Chemists International. 16 ed. Washington: Williams Horwitz, 1997. 1141p. BLIGH, E.G. e DYER, W.J. A rapid method of total lipid extraction and purification. Canadian Journal Biochemistry and Physiology, Ottawa,v.37, n.8, p.911-917, 1959.

CARSON, J.K. Review of effective thermal conductivity models for foods. International Journal of Refrigeration, Oxford, v.29, n.6, p.958-967, 2006.

CENGEL, Y. A. Heat transfer - a practical approach. $3^{\text {a }}$. ed. New York: McGraw-Hill, 2004. 908p.

DICKERSON, R.W. An apparatus for measurement of thermal diffusivity of food. Food Technology, Chicago, v.5, n.19, p.198-204, 1965.

FARAG, K.W.; LYNG, J.G.; MORGAN, D.J.; CRONIN, D.A. Dielectric and thermophysical properties of different beef meat blend over a temperature range of -18 to $+10^{\circ} \mathrm{C}$. Meat Science, Oxford, v.79, n.4, p. 740-747, 2008.

GALÃO, O. F.; PINTO, J. P.; BORSATO, D. Análise e aproveitamento da gordura de resíduos de abatedouros de aves. Semina: Ciências Exatas e Tecnológicas, Londrina, v. 24, p. 93-96, 2003.

GONZO, E.E. Estimating correlations for the effective thermal conductivity of granular materials. Chemical Engineering Journal, Oxford, v.90, n.9, p.299-302, 2002.

HUANG, L. e LIU, LIN-SHU. Simultaneous determination of thermal conductivity and thermal diffusivity of food and agricultural materials using a transiente plane-source method. Journal of Food Engineering, Oxford, v.95, n.1, p.179-185, 2009.

KARUNAKAR, B.; MISHRA, S.K.; BANDYOPADHYAY,S. Specific heat and thermal conductivity of shrimp meat. Journal of Food Engineering, Oxford, v.37, n.3, p.345351, 1998.

MARCOTTE, M.; TAHERIAN, A.R.; KARIMI, Y. Thermophysical properties of processed meat and poultry products. Journal of Food Engineering, Oxford, v.88, n.3, p.315-322, 2008.

MOHSENIN, N.N. Physical properties of plant and animal materials. New York: Gordon \& Breach Sci., 1986. 922p.

OLIVEIRA, G.S. et al. Thermo-physical properties of cooked ham. International Journal of Food Properties, Philadelphia, v.8, n.2, p.387-394, 2005.

RACANICCI, A. M. C. et al. Oxidação lipídica do óleo de vísceras de aves para redução de seu conteúdo de energia metabolizável para frangos de corte na fase de crescimento. Revista Brasileira de Zootecnia, Viçosa, v. 33, n. 4, p. 919-923, 2004.

SAHIN, S.S.; SUMMU, S.G. Physical properties of foods. New york: Ed. Springer, 2006. $257 \mathrm{p}$.

TBCA/USP. UNIVERSIDADE DE SÃO PAULO. Faculdade de Ciências Farmacêuticas. Departamento de Alimentos e Nutrição Experimental/BRASILFOODS (1998). Tabela Brasileira de Composição de Alimentos-USP. Versão 5.0. Disponível em: http://www.fcf.usp.br/tabela. Acesso em: 17.09.2012.

UNKLESBAY, N.; UNKLESBAY, K.; CLARKE, A.D. Thermal properties of restructured beef snack sticks throughout smokehouse processing. WLT-Food Science and Technology, Amsterdam v.32, n.8, p.527-534, 1999.

WANG, J.F.; NORTH, M.F.; CLELAND, D.J. A new approach to the modeling of the effective thermal conductivity of heterogeneous materials. International Journal of Heat and Mass Transfer, Oxford, v.49, n.17-18, p.3075-3083, 2006. 